\title{
Reflexiones sobre el abordaje de la política y cultura de masas en entreguerras: escalas, conceptos, problemas
}

\author{
Considerations on the approach of politics and mass culture in the interwar \\ period: scales, concepts, problems.
}

\author{
Mariela Rubinzal \\ mariela.rubinzal@gmail.com \\ Instituto de Humanidades y Ciencias Sociales - \\ CONICET - Universidad Nacional del Litoral, \\ Argentina
}

Cita sugerida: Rubinzal, M. (2021). Reflexiones sobre el abordaje de la política y cultura de masas en entreguerras: escalas, conceptos, problemas. Sociohistórica, 47, e128. https://doi.org/10.24215/18521606e128

\begin{abstract}
Resumen: En este trabajo se exponen reflexiones sobre el abordaje de la política y cultura de masas en entreguerras desde una perspectiva que pone en juego conexiones entre las industrias culturales y la política entendida en un sentido amplio. La consolidación de las industrias culturales es un hecho social ineludible del proceso de modernización y un lente privilegiado para acceder a nuevas dimensiones de la vida política y cultural de este período. Las categorías, los marcos cronológicos, los diseños de la investigación y las fuentes constituyen momentos y decisiones que han sido analizados en diálogo con otros saberes.

Palabras clave: Reflexiones, Política, Cultura, Industrias culturales, Entreguerras.

Abstract: This paper sets out reflections on the approach of mass politics and culture in interwar period from a perspective that brings into play connections between the cultural industries and politics understood in a broad sense. The consolidation of cultural industries is an inescapable social fact of the modernization process and a privileged lens to access new dimensions of political and cultural life of this period. Categories, chronological frameworks, research designs and sources are moments and decisions that have been analyzed in dialogue with other knowledge.
\end{abstract}

Keywords: Reflections, Politics, Culture, Cultural industries, Interwar.

\section{DE LAS PRÁCTICAS DE INVESTIGACIÓN EN HISTORIA}

El campo de análisis en el que se insertan estas reflexiones sobre prácticas y experiencias de investigación es el de las conexiones entre las industrias culturales y la política entendida en un sentido amplio. Las grandes transformaciones que se registraron en el período de entreguerras tuvieron un impacto en el mundo de la cultura a partir de la creación de nueva infraestructura (teatros, cines, emisoras radiofónicas, editoriales), incorporación de nuevas tecnologías y conformación de un público nuevo. Desde este prisma, la consolidación de las industrias culturales es un hecho social ineludible del proceso de modernización y, por lo tanto, un lente privilegiado para observar los vínculos entre la política y la cultura en tanto estas inciden en el plano de simbólico impulsando -entre otras cosas- la formación de identidades sociales y políticas. 
En consonancia con la idea de que los procesos culturales se desarrollan en el longue durée, hemos optado por los recortes cronológicos que permiten mirar el desarrollo de dispositivos culturales que, sin lugar a duda, fueron adquiriendo un lugar predominante en la vida cotidiana de los ciudadanos. A partir de la lectura de las fuentes primarias, hallamos una conexión entre el impulso de las industrias culturales y el interés de las distintas culturas políticas por las mismas con la ampliación efectiva de la participación política. En efecto, en la ciudad de Santa Fe durante los años de la Primera Guerra mundial existió un consumo relativamente alto de productos culturales (especialmente cinematográficos) que se profundizó, amplificó y diversificó en los años veinte (Rubinzal, 2018). En este punto, la flexibilidad del diseño (ver Piovani, 2018) de la investigación es una necesidad del oficio de investigar en historia en tanto las vicisitudes en los archivos y los hallazgos de las fuentes históricas van redireccionado la búsqueda inicial (Caimari, 2017), que en nuestro caso estaba centrada en los años treinta. El trabajo en los archivos exige no sólo mantenerse en estado de alerta para seguir un rastro inesperado sino también la capacidad de reflexionar sobre esos redireccionamientos que demuestran conexiones poco evidentes. Esto también implica que el trabajo con las fuentes primarias (al menos el relevamiento, sistematización y primer abordaje) no suele ser unidireccional.

La perspectiva teórica toma insumos de la historia política en diálogo con la historia social y los estudios culturales. Esta triangulación de aportes permite pensar una serie amplia de interrogantes: cuáles fueron las características predominantes del cine, la radio y las ediciones locales; qué tipo de productos circulaban y por qué vías; cuáles eran las representaciones sobre la cultura de masas que prevalecían entre los intelectuales, los funcionarios y los empresarios locales; si existieron conflictos entre el estado y el mercado profundizando en sus motivos e implicancias tanto en el mundo de la política como en la esfera de la cultura; cómo las personas vivían los hechos culturales e incorporaban prácticas y productos a su vida cotidiana. Al trabajar con un pasado inaccesible por medio de entrevistas a quienes vivieron y consumieron los productos culturales, esta última cuestión -la recepción de los productos culturales- sólo puede restituirse de forma marcadamente fragmentaria en base a algunas memorias, cartas de lectores, narrativas familiares o fotografías de la época.

No obstante, y a pesar de los límites planteados, se sostiene la validez y la riqueza de este tipo de abordaje que profundiza en las relaciones entre el estado, la sociedad y el mercado, desde diferentes campos del conocimiento social, incorporando categorías y desarrollos teóricos de la antropología, la sociología y los estudios culturales. ${ }^{1}$ En lo empírico se producen datos cualitativos a partir de diferentes técnicas como el análisis documental, la reconstrucción de trayectorias biográficas, el análisis de discursos y elaboración de mapas del consumo (información de tipo cuantitativa).

\section{DE LOS CONCEPTOS Y CATEGORÍAS}

La cultura de masas configuró una temática central en la agenda de intelectuales y políticos durante el período de entreguerras. La tarea de pensar una nación conformada por culturas heterogéneas en medio de una crisis mundial y del avance de los autoritarismos (internacionales y locales) insertaba en el debate motivos como la lengua, las costumbres, las raíces, el pasado común y el "alma nacional”, entre otros. Tanto Rafael Araya como José Babini (referentes intelectuales en la región) pensaban en la cultura como factor de integración en el plano colectivo y de elevación personal en el individual. Ambos sostenían que la universidad tenía una función social que excedía ampliamente la formación de expertos y que debía socializar el conocimiento que se producía intramuros haciendo uso de las nuevas tecnologías (Rubinzal, en prensa). El contrapunto fue la emergencia de ideas perturbadoras acerca de los efectos de las industrias culturales en las personas que carecían de instrucción, valores o convicciones religiosas fuertes para contrarrestar la supuesta pulsión al crimen, al sexo o a la disidencia respecto el orden establecido. En esta zona gris de expectativas, temores, desacuerdos, conflictos y pasiones reside uno de los aspectos más interesantes de la emergencia de las industrias culturales a principios del siglo XX. 
Afortunadamente existen estudios recientes que abordan las formas en que las culturas políticas, la cultura católica y las organizaciones sindicales incorporaron las industrias culturales para difundir, reforzar y ampliar la llegada de sus ideas, o al menos reconocieron que se trataba de recursos tecnológicos poderosos que representaban la modernidad de la época y no podían ser ignorados o simplemente censurados (Acha y Ben, 2004; Lida, 2005; Mauro, 2008; Gené, 2008; Fiorucci, 2009; Karush \& Chamosa, 2010; Cortes Rocca, Dieleke y Soria, 2010; Karush, 2013; Caruso, 2015; Buonuome, 2016; Cattaruzza, 2016 y 2018; Gayol, 2016; Gayol y Palermo 2018; Guiamet, 2017; Rubinzal y Zanca, 2015; Rubinzal, 2016 y 2019; Zanca, 2016). La relevancia de esta constatación es la ampliación del campo de estudio de la historia política a partir de la inclusión de gestos, hechos, discursos y prácticas que siendo efectuados por actores ajenos a la política ejercen una acción significativa en ese espacio. De esto se desprende que la cultura, claramente, lejos de permanecer como un ámbito ligado al arte y la erudición habitado fundamentalmente por las elites, se abre para incluir a las masas creando espacios de contacto "donde las fronteras que separan a los diferentes sectores tienen una relativa porosidad, que genera nuevas formas de intercambios simbólicos y políticos" (Montaldo, 2016, p. 13). Es en esa zona donde se construyen nuevas sociabilidades y se delinean identidades politizando la cultura al tramitar las tensiones y los conflictos propios de la modernización.

De esta manera, subrayamos la dimensión política de la cultura de masas en tanto los productos culturales intervienen en la construcción y circulación de identidades, valores y motivos que podrían inspirar la acción política (Karush, 2013), cualidad que tenían muy claro, por ejemplo, los fascismos (Rubinzal, 2016; Rubinzal, en prensa). Allí donde Adorno y Horkheimer vieron alienación y manipulación totalitaria, había efectivamente una clave perdurable de la política del siglo XX. El concepto de industria cultural proviene del famoso texto de estos autores titulado Dialektik der Aufklärung(1944) en el cual extienden la crítica de la modernidad ilustrada a la producción artística desarrollada sobre las nuevas tecnologías (la fotografía, la radio, el cine). A partir de los años sesenta ${ }^{2}$ las industrias culturales van a ser pensadas como espacios de condensación e intersección de redes culturales múltiples, conformadas por dispositivos complejos que no son de orden meramente tecnológico, mercantil o político. Los estudios actuales sobre las industrias culturales señalan la capacidad de estas para incidir en la pugna de sentidos, pero no de una forma monolítica sino variada y polisémica. La influencia de dichas industrias en la creación y definición de identidades (cualidad que la diferencia de otro tipo de industrias) tiene a su vez una dimensión trasnacional visible en la circulación de estos bienes, en la conformación de las empresas y en el impacto de sus productos.

Las conexiones con la política permiten ver aún con más claridad de qué formas la cultura funciona como un espacio de disputa ( Hall, S. y Jefferson, T.,1983; Hoggart, [1957] 2013) por la apropiación de los objetos culturales o por la interpretación de los hechos de cultura. Esto confirma la idea de que el consumo cultural es un proceso activo de producción de sentidos (Levine, 1992) y las mercancías producidas por las industrias culturales son inherentemente polisémicas. El caso del nacionalismo argentino es interesante en la medida que se puede trazar una interpretación de su evolución política a través de sus productos culturales, esto es, desde sus inicios elitistas alrededor del diario La Nueva Republica hasta la proliferación de una docena de periódicos y editoriales cuyo catálogo incluía libros dirigidos a los sectores populares. En la obra historiográfica Los nacionalistas, María Inés Barbero y Fernando Devoto señalaron que en sus orígenes el nacionalismo fue "un movimiento cultural acotado", encarnado por personas que tenían "una conciencia de pertenencia" a dicho movimiento y que compartían ciertos rasgos político-ideológicos (Barbero y Devoto, 1983, p. 10). Olga Echeverría señala que -a pesar de la heterogeneidad de ideas y la fragmentación de esta configuración política autoritaria- compartían el rechazo de las expresiones de la cultura popular. Las voces autoritarias se hacen más insistentes en la medida en que se consolida una cultura de masas y comienzan a circular productos para amplios sectores de la sociedad; "lo que molestaba a los pensadores antidemocráticos no era la existencia de esa cultura 'desviada e indigna', sino su visibilidad y su irrupción en ámbitos antes restringidos y selectos” (Echeverría, 2013, p. 64). 
Sin embargo, una mirada de largo alcance demuestra que, a partir del golpe de Estado del 6 de setiembre de 1930, gran parte del nacionalismo adopta nuevas características en lo estructural (Mc Gee Deutsch, 2005; Klein, 2000), en lo doctrinario (Spektorowski, 1991), y también en lo cultural (Rubinzal, 2016). Otros enfoques y diferentes actores le dieron vida a un nacionalismo combatiente que decidió salir a las calles con la pretensión de movilizar a todos los sectores sociales, incluyendo a los trabajadores a los cuales pretendían representar y alejar definitivamente de las culturas de izquierda. Es cierto que esta tendencia convivió con una vertiente tradicionalista y contraria a las manifestaciones populares, por lo cual parece pertinente utilizar el concepto de cultura politica como

un agregado de subculturas, con normas y valores diversos (...) pero también con líneas de contacto que posibilitan el consenso, la convivencia, la solidaridad, el reclutamiento, la movilización o el mantenimiento de las tradiciones cognitivas necesarias para sostener el activismo, o revitalizarlo tras un posible período de inactividad o declive del movimiento (González Calleja, 2003, p. 110).

Los nacionalistas demostraron una gran preocupación por la cuestión cultural. Los objetivos principales eran resguardar los valores tradicionales y católicos difundiendo ideas autoritarias por vías alternativas e incorporando las demandas de los sectores trabajadores. También intentaron difundir sus doctrinas con un lenguaje sencillo y pedagógico denunciando situaciones de injusticia social provocadas por la "codicia" capitalista. Las publicaciones periódicas nacionalistas comenzaron a editar libros de bajo costo para sus suscriptores de todo el país, siguiendo así una tendencia instalada en el mercado desde fines del siglo XIX. ${ }^{3}$ Paralelamente fueron generando otras actividades culturales organizadas y promovidas para sus lectores, quienes combinaban la lectura solitaria con la participación en eventos realizados en teatros, cines, o espacios abiertos; muchos lectores, incluso, realizaron viajes a Europa organizados por los editores de los periódicos. A partir esto, se ha argumentado que en entreguerras se consolidó la proliferación de publicaciones periódicas que funcionaron como verdaderos dispositivos culturales(Rubinzal y Zanca, 2015) a través de los cuales se organizaban otros consumos (radiales, musicales y cinematográficos) y se promovieron prácticas colectivas con los lectores (encuentros, veladas musicales, viajes culturales, etc.). Por ejemplo, el periódico nacionalista Crisol -que editaba su propia colección de libros a bajo costo- decía que las obras de los escritores nacionalistas servirían para "contrarrestar los efectos perniciosos" de las novelas "vulgares" que "envenenaban" el alma (Crisol, 6/02/1936: 3). Para frenar la circulación de las novelas populares que juzgaban "vulgares", "socialistas" o "eróticas" había que editar libros recomendables que se vendieran en el mercado a "precios accesibles a todos los bolsillos."(Crisol, 18/07/1937: 4) Crisol ofreció a sus lectores y "amigos" una lista de libros que se podían comprar en la administración y que también se podían enviar al interior del país. Lejos de ser un atributo de las publicaciones periódicas nacionalistas esta matriz se encuentra en proyectos editoriales de otros signos políticos, religiosos y comerciales. ${ }^{4}$

La "cruzada" que los nacionalistas emprendieron durante los años treinta en defensa de la nación incluyó el objetivo de restituir a las mujeres al universo de sus hogares y a sus funciones reproductivas. ${ }^{5}$ Las novelas de escritores nacionalistas tenían la función de "resistir" en el orden de lo cultural las consecuencias de la emergencia y propagación de las mujeres en el mercado de trabajo, y también difundir en los hogares argentinos los principios del nacionalismo a través de las madres-lectoras. Las novelas de Juan Carlos Moreno ${ }^{6}$ sobre el mundo del trabajo y las mujeres constituyen un corpus de textos que se proponían revertir la “degradación moral", recristianizar a los sectores populares y preservarlos de las influencias de la izquierda.

Constatar la existencia de trabajadores que efectivamente adhirieron a las derechas posibilita pensar la construcción de identidades como un fenómeno complejo en el cual intervienen distintas variables. ${ }^{7}$ Los productos culturales, al tiempo que buscan identificar al lector/espectador/oyente con "lo representado", abren un abanico de rasgos identitarios iluminando siluetas de esos lectores "reales" a los cuales se pretende movilizar. En este sentido la ficción puede decirnos mucho sobre ese mundo histórico del cual surge, de las personas a las cuales intenta seducir $y$, obviamente, de quien escribe esas páginas, dirige un film o produce 
un programa radial. La ficción, o el melodrama, pudo haber inspirado acciones políticas (Karush, 2013) al sintetizar antagonismos visibles y tensiones soterradas, aunque habilitando múltiples sentidos posibles para un mismo relato.

\section{DE LAS TEMPORALIDADES Y LAS ESPACIALIDADES}

El periodo de entreguerras ha sido profusamente estudiado tanto desde la historiografía como desde los estudios culturales. Desde la historia política, se han distinguido algunos nudos histricos entre la ampliación de la participación electoral mediante la sanción de la Ley Sáenz Peña y los orígenes del peronismo. En esa línea que abarca casi toda la primera mitad del siglo XX habitan diferentes posibles cronologías, sobre todo si partimos de la base que un recorte temporal es en sí mismo arbitrario y, frecuentemente, solo adquiere sentido en la lógica misma de la investigación justificándose por su función instrumental. Ahora, cuando se trabaja en una zona de intersección como la nuestra, se corre el riesgo de imponer la cronología política a otros espacios como el de la cultura. Evitar este riesgo supone adoptar un modo anfibio que permita dar cuenta de los cruces y las especificidades de cada ámbito sin forzamientos. En nuestra investigación la cronología fue en sentido inverso (aspecto bastante común en las investigaciones históricas), ya que al partir del examen de la larga dcada de 1930 hubo que retroceder al contexto de la Primera Guerra Mundial. Entonces un (primer) segmento va de 1914 a 1930, ya que por estos años la provincia de Santa Fe experimentó una verdadera explosión demográfica, al registrar 900.000 habitantes en 1914, gracias al impacto de la inmigración y a la revolución agropecuaria que se concentró sobre todo en el centro y sur provincial. En las ciudades de Rosario y Santa Fe la población creció exponencialmente: de 92.717 habitantes (en 1895) Rosario pasó a tener 226.241 en el año 1914; de 22.244 habitantes (en 1895) Santa Fe pasó a tener 59.574 al comenzar la Primera Guerra Mundial. El nacionalismo reaccionó ante lo que Beatriz Sarlo ha denominado "cultura de mezcla”, producto de una población plural en trminos lingísticos y de orígenes nacionales en el contexto de un proceso de cambios profundos que conmovieron las ideas, sentimientos y sensaciones de toda una generación. Algunos rasgos de este momento histórico son la profundización de la conflictividad social; los debates sobre la reforma política de 1912; el impacto de la Gran Guerra y la Revolución Sovitica y la Reforma Universitaria de Córdoba de 1918. Claramente hacia la Primera Guerra Mundial un número importante de intelectuales comenzaron a percibir al "progreso" como negativo, a la vez que señalaron la existencia de una "crisis moral" que afectaba a distintos sectores de la sociedad (Terán, 2004). Este período, signado por la crisis de la hegemonía del positivismo, del liberalismo y por la emergencia de "nuevas sensibilidades", dio lugar a la aparición de escritores, periodistas y ensayistas que comenzaron a transitar derroteros antiliberales, como el clebre Leopoldo Lugones desde las páginas del periódico La Nacin. En este marco las industrias culturales adquirieron un rol fundamental como expresión de una sociedad que se transformaba y se democratizaba a partir de la expansión del consumo de bienes culturales.

Sobre el segmento comprendido entre el primer golpe de Estado y la finalización de la Segunda Guerra Mundial (1930 y 1945), se advierte que las diferentes culturas políticas coincidieron en la importancia del cine, la radio y la literatura haciendo un uso político de las mismas; y que algunas políticas culturales tuvieron a nivel local una notable continuidad, siendo sostenidas por gestiones gubernamentales de signos políticos antagónicos. Los funcionarios y gestores culturales tienen una especial relevancia para una investigación de este tipo ya que son quienes piensan, escriben e implementaban las políticas culturales. En este sentido las biografías tienen la capacidad de brindar datos para reconstruir sentidos, imágenes y prácticas de la época.

A contrapelo de la imagen socialmente más difundida -los años treinta como la "década infame", "los años oscuros"- hay un amplio consenso historiográfico en el sentido de subrayar los procesos de modernización que signaron esta época y delinearon tanto el desarrollo como los conflictos futuros. El impacto de las industrias culturales en la sociedad de masas es un fenómeno trasnacional, que asumió características específicas en los ámbitos nacionales. La perspectiva transnacional, que ha ganado importancia académica en los últimos años, 
no significa perder de vista las particularidades sino posibilitar la comprensión de la difusión y circulación de ciertos productos culturales. Esto es particularmente cierto con los libros, la cinematografía y, por supuesto, las ideas que sobre las industrias culturales se estaban gestando, en diversos países del continente americano y europeo, que han influido notablemente en los escritores, críticos y realizadores argentinos.

\section{DE LA RIGUROSIDAD Y LA CREATIVIDAD}

Un problema recurrente en las investigaciones históricas y sociales es la cuestión de la validez de los resultados. La superación de los enfoques positivistas ha propiciado la emergencia de un escenario plural, contingente y dinámico, el cual contrasta con la (más bien lenta) adecuación de las instituciones y de las distintas comunidades académicas a dichas circunstancias. El paradigma interpretativo asumió conscientemente el rol de la creatividad a la vez que dejó borroso el tema de una nueva rigurosidad científica. Esto implica, por un lado, una reubicación del sujeto cognoscente munido de herramientas teórico-metodológicas pero también de intenciones, de valores, intereses y condicionamientos cuyo impacto en una investigación es innegable. Así, la definición de la investigación como una práctica histórica y la implicación subjetiva de quienes investigamos se ha convertido en un andamiaje común de las investigaciones sociales. No obstante, el problema de la validez subsiste en diferentes planos del proceso de investigación: fuentes, metodología, marco conceptual, diseño. Algunas perspectivas, tales como las indigenistas o las feministas, han cuestionado la idea tradicional de validez de la ciencia proponiendo nuevos protocolos de investigación.

Para quienes historiamos el pasado un problema crucial es la validez de las fuentes. Ya sea que trabajemos con entrevistas en profundidad (historia oral), con documentos institucionales, con la prensa o con un corpus de filmes - por nombrar solo algunos de los tantos tipos de fuentes con los que trabajamos-, la pregunta sobre la validez y suficiencia del corpus remite a si hemos alcanzado el punto de saturación. Dice Bertaux: "cuando se alcanza, confiere una base muy sólida a la generalización: a este respecto cumple, por lo que hace a la perspectiva biográfica, exactamente la misma función que la representatividad de la muestra para la investigación mediante cuestionarios" (Bertaux, 2011). Ya sea que se intente enunciar hipótesis con cierto grado de generalidad, o bien que se trate de una investigación circunscripta a un evento local o individual, el "punto de saturación" del que habla Daniel Bertaux representa un estado de exhaustividad aceptable para la comunidad académica y sobre el cual se supone el investigador podrá reflexionar con mayores elementos, y ofrecer así resultados concluyentes. Al ampliar la noción de "punto de saturación”, tal como la definió Bertaux, entendemos que se trata no de un determinado volumen de datos sino de un momento de la investigación, en el cual más allá de la cantidad y diversidad de las fuentes -condicionamientos necesarios de la investigación historiográfica- se puede arribar a reflexiones profundas sobre el objeto de estudio. Como dice Giovanni Levi, el historiador no apunta a generalizar respuestas, sino que, a través de un hecho, un lugar, un documento, un acontecimiento -leídos gracias a una ampliación de escala en un microscopio-, quiere identificar preguntas que tienen un valor general, pero que dan lugar a un amplio espectro de respuestas diferentes (Levi, 2018).

La creatividad está muy presente en el esfuerzo literario que implica toda publicación de una investigación. El momento de la escritura conlleva una rememoración de los hallazgos, de las inflexiones, de las reflexiones que supuso cada momento de la investigación organizando los retazos significativos que resurgen a la hora de comunicar lo investigado. De alguna manera se trata de un momento de introspección que supone una serie de movimientos y operaciones internas: los investigadores piensan al escribir, analizan escribiendo y sintetizan ideas por medio de la escritura. Irene Vasilachis recoge una idea de escritura científica (tomada de Richardson y St. Pierre) "como un método de investigación, una condición de posibilidad tanto para producir un conocimiento diferente como para producir conocimiento de manera diferente." (Vasilachis de Gialdino, 2017). La creación de sentidos por medio de la escritura es un aspecto fundamental del oficio de investigar, 
en el que se ponen en juego una serie de asociaciones, expresiones, vinculaciones e imágenes que son la marca de quien escribe, de la época y del lugar desde donde lo hace.

\section{A MODO DE SÍNTESIS}

En este trabajo se reflexionó sobre el abordaje de la política y la cultura de masas durante la primera mitad del siglo XX a partir de algunos ejes centrales: la práctica y el diseño de la investigación, los conceptos y categorías, las temporalidades y el trabajo con las fuentes a partir de la idea de "rigurosidad" y "creatividad". Destacando algunas de las limitaciones que surgen en el recorrido de una investigación de este tipo, se pusieron de relieve las posibilidades que brinda la triangulación de diferentes campos disciplinares para dar cuenta de procesos que incluyen tanto transformaciones materiales como simbólicas perdurables.

\section{REFERENCIAS}

Acha, O., y Ben, P. (2004). Amorales, patoteros, chongos y pitucos. La homosexualidad masculina durante el primer peronismo (Buenos Aires, 1943-1955). Trabajos y Comunicaciones, 2a época, 30-31, 217-260.

Adorno, T. W. y Horkheimer, M. (1997 [1944]). Dialéctica del iluminismo. Buenos Aires - México: Sudamericana / Hermes.

Appadurai, A. (ed.) (1991). La vida social de las cosas. Perspectiva cultural de las mercancías. México: Grijalbo.

Barbero, M. I. y Devoto, F. (1983). Los Nacionalistas. Buenos Aires: CEAL.

Bertaux, D. (2011). El enfoque biográfico: su validez metodológica, sus potencialidades. Acta Sociológica, núm. 56, 61-93. https://doi.org/10.22201/fcpys.24484938e.2011.56.29458.

Buonuome, J. (2016). El partido de los consumidores. Publicidad, consumo y cultura de clase en la prensa socialista argentina, entre el Centenario y la Gran Depresión. Desarrollo Económico, 56(219), 245-276.

Bourdieu, P. (2006) La distinción: criterios y bases sociales del gusto. Madrid: Taurus.

Burke, P. (2000). Formas de historia cultural. Madrid: Alianza.

Caimari, L. M. (2017). La vida en el archivo: goces, tedios y desvios en el ficio de la historia. Buenos Aires: Siglo Veintiuno Argentina.

Cattaruzza, A. (2018). Un siglo de libros de historia en la Argentina: La cultura, la política y el mercado editorial. Badebec, 8(15), 199-235.

Cattaruzza, A. (2016). Las culturas políticas en la Argentina de los años treinta: algunos problemas abiertos. Anuario del Instituto de Historia Argentina, 16(2), e018. Recuperado de https://www.anuarioiha.fahce.unlp.edu.ar/arti cle/view/IHAe018

Caruso, L. (2015). El sindicato marítimo en el éter: Audiciones radiales de un gremio en la Argentina de los años '30. Avances Del Cesor, 12(12), 53-70.

Cortes Rocca, P., Dieleke, E., y Soria, C. (2010). Políticas del sentimiento: El peronismo y la construcción de la Argentina moderna. Buenos Aires: Prometeo Libros.

Echeverría, O. (2013). Los intelectuales antidemocráticos frente a lo popular. Argentina, primera mitad del siglo XX. Historia y Espacio, 40, 49-73.

Fiorucci, F. (2009). La cultura, el libro y la lectura bajo el peronismo: El caso de la Comisión de Bibliotecas Populares. Desarrollo Económico, 48(192), 543-556.

Gayol, S. (2016). La muerte en espejo: Movilizaciones, emociones y política de masas. Anuario del Instituto de Historia Argentina, 16(2), e019-e019. Recuperado de https://www.anuarioiha.fahce.unlp.edu.ar/article/view/IHAe019

Gayol, S., y Palermo, S. A. (2018). Política y cultura de masas en la Argentina de la primera mitad del siglo XX. Buenos Aires: Universidad Nacional General Sarmiento.

García Canclini, N. (2000). Culturas hibridas: estrategias para entrar y salir de la modernidad. México: Grijalbo [u.a.]. 
Gené, M. M. (2008). Un mundo feliz: Imágenes de los trabajadores en el primer peronismo, 1946-1955. Buenos Aires: Fondo de Cultura Económica.

Geertz, C. (1996). La interpretación de las culturas. Barcelona: Gedisa.

Geertz, C. (2011). Conocimiento local: ensayos sobre la interpretación de las culturas. Barcelona: Paidós.

González Calleja, E. (2003). Aproximación a las subculturas violentas de las derechas antirrepublicanas españolas (1931-1936). Pasado y memoria, 2, 107-141.

Guiamet, J. (2017). Tentaciones y prevenciones frente a la cultura de masas. Los socialistas argentinos en el periodo de entreguerras (Tesis Doctoral), Universidad Nacional de La Plata, Argentina.

Hall, S. y Jefferson, T. (Eds.) (1983). Resistance through rituals. Youth subcultures in postwar Britain. Hutchinson University London.

Hall, S. (1992). Cultural Studies and its Theorethical Legacies. En L. Grossberg, N. Cary y P. Treichler (ed.), Cultural Studies. Nueva York: Routledge.

Hoggart, R. ([1957] 2013). La cultura obrera en la sociedad de masas. Buenos Aires: Siglo XXI.

Karush, M. B. (2013). Cultura de clase. Radio y cine en la creación de una Argentina dividida (1920-1946). Buenos Aires: Ariel.

Karush, M. B., \& Chamosa, O. (2010). The new cultural history of Peronism power and identity in mid-twentieth-century Argentina. Durham, NC. Duke University Press.

Klein, M. (2000). A Comparative Analysis of Fascist Movements in Argentina, Brazil, and Chile. Between the Great Depression and the Second World War (Thesis submitted for the degree of Doctor of Philosophy of the University of London), London, Institute of Latin American Studies, School of Advanced Study.

Levi, G. (2018). Microhistoria e Historia Global. Historia Critica, 69, 21-35.

Levine, L. W. (1992). The Folklore of Industrial Society: Popular Culture and Its Audiences. American Historical Review, 97(5), 1369-1399.

Lida, M. (2005). Catecismo, cine y golosinas. Iglesia católica y la infancia a comienzos del siglo XX. Todo es historia, 457, 30-37.

Mc Gee Deutsch, S. (2005). Las derechas. La extrema derecha en la Argentina, el Brasily Chile. 1890-1939. Buenos Aires: Universidad Nacional de Quilmes Editorial.

Mauro, D. (2008). Las voces de Dios en tensión. Los intelectuales católicos entre la interpretación y el control. Santa Fe, 1900-1935. Signos Históricos, núm. 19,128-154.

Mignolo, W. (2015). Habitar la frontera: Sentir y pensar la descolonialidad. (Antología, 1999-2014). Barcelona, CIDOB y UACJ, Edicions Bellaterra, S.L.

Montaldo, G. (2016). Museo del consumo: Archivos de la cultura de masas en Argentina. Buenos Aires: Fondo de Cultura Económica.

Monsiváis, C. (2000). Aires de familia: cultura y sociedad en América Latina. Barcelona: Editorial Anagrama.

Piovani, J. I. (2018). Reflexividad en el proceso de investigación social: entre el diseño y la práctica. En J. I. Piovani, L. Muñiz Terra y D. Baranger, ¿Condenados a la reflexividad?: apuntes para repensar el proceso de investigación social (pp. 74-92)1. Buenos Aires: CLACSO.

Rubinzal, M. (2016). La cultura combate en las calles. Nacionalismo e industrias culturales en la Argentina de entreguerras. Anuario del Instituto de Historia Argentina, 16(2), e022. Recuperado de https://www.anuarioiha .fahce.unlp.edu.ar/article/view/IHAe022

Rubinzal, M. (2018). El caso del cinematógrafo escolar en entreguerras: tensiones entre Estado, mercado y política en Santa Fe. En S. Gayol y S. A. Palermo, Politica y cultura de masas en la Argentina de la primera mitad del siglo XX (pp. 73-97). Buenos Aires: Ediciones Universidad Nacional de General Sarmiento.

Rubinzal, M., y Zanca, J. (2015). «Primeras Armas» y sus pequeños lectores en la Argentina católica de entreguerras. Iberoamericana (2001-), 15(60), 117-132. 
Rubinzal, M. (en prensa). Las industrias culturales y la Universidad Nacional del Litoral. El Instituto Social (1928-1943). En M. Rubinzal (compiladora) (en prensa), La política y la cultura bajo la lupa. Estudios interdisciplinarios socioculturales. Santa Fe, siglo XX. Santa Fe: Ediciones UNL.

Rubinzal, M. (en prensa). La circulación cultural de las derechas en la Argentina: el caso del nacionalsocialismo y la Comisión Especial Investigadora de Actividades Antiargentinas (1941 - 1943). El Congreso de ayer a hoy. Direcciones de Cultura del Congreso de la Nación, Buenos Aires.

Sagastizábal, L. de (1995). La edición de libros en la Argentina: Una empresa de cultura. Editorial Universitaria de Buenos Aires.

Beverly S. (2005). Fuerzas de trabajo. Los movimientos obreros y la globalización desde 1870. Madrid: AKAL.

Spektorowski, A. (1991). Argentina 1930 - 1940: nacionalismo integral, justicia social y clase obrera. Estudios Interdisciplinarios de América Latina y el Caribe, 2(1), 61-79.

Terán, O. (2004). Ideas en el siglo. Intelectuales y cultura en el siglo XX latinoamericano. Buenos Aires: Siglo XXI.

Vasilachis de Gialdino, I. (2017). Investigación cualitativa: epistemologías, validez, escritura, poética, ética. En N. Denzin y Y. Lincoln (comps.), El arte y la práctica de la interpretación, la evaluación y la presentación, Volumen $V$ Manual de Investigación cualitativa (pp.11-45). Buenos Aires: Gedisa [Colección Herramientas Universitarias].

Williams, R. (1997). Marxismo y literatura. Barcelona: Península.

Zanca, J. (2016). Cultura católica y política en el período de entreguerras, mito, taxonomía y disidencia. Anuario del Instituto de Historia Argentina, 16(2), e021. Recuperado de https://www.anuarioiha.fahce.unlp.edu.ar/article/ view/IHAe021

\section{Notas}

1 Los textos canónicos sobre la temática aportan insumos ineludibles para insertar el problema planteado en un horizonte teórico. Al respecto se pueden mencionar algunos: Geertz, 1996; Geertz, 2011; Bourdieu, 2006; Burke, 2000 ; Hall, 1992. También se consideran fundamentales las teorías provenientes de la perspectiva decolonial: Monsiváis, 2000; García Canclini, 2000; Appadurai, 1991; Mignolo, 2015.

2 El texto clave en estos años es el de Edgar Morin (El Espiritu del tiempo: ensayo sobre la cultura de masas) en el cual demuestra, a propósito del cine especialmente, cómo la división del trabajo y la mediación tecnológica no son incompatibles con la «creación» artística; argumentando que incluso la estandarización no implica la anulación de la experiencia creativa (esa zona de creación y talento que no desaparece).

3 El proyecto editorial impulsado por Emilio Mitre, director de La Nación, fue el más significativo de este período por su calidad, éxito y continuidad. La "Biblioteca de la Nación” reunió 875 títulos editados durante 20 años y se convirtió en "un verdadero fenómeno cultural” (De Sagastizábal, 1995, p. 47).

4 Algunos ejemplos de esta lógica editorial está presente en la Cooperativa Editorial Claridad y en el diario Crítica.

5 En este aspecto no eran originales: otros discursos sociales de la época, inclusive algunos provenientes de la izquierda, también adherían a los principios de la ideología de la domesticidad, al afirmar que las tareas domésticas definían la identidad femenina.

6 Juan Carlos Moreno era un escritor y periodista que escribía habitualmente para Crisol y Criterio. En los años cuarenta colaboró en la revista Nueva Política, dirigida por Marcelo Sánchez Sorondo, cuyos redactores eran reconocidos miembros del nacionalismo (por ejemplo Héctor Bernardo, Alberto Ezcurra Medrano, Federico Ibarguren, Bruno Jacovella, Héctor A. Llambías y Juan Carlos Villagra). Moreno visitó las fábricas y los talleres de Buenos Aires con el objetivo de recabar insumos para sus escritos, que en gran proporción describían distintos aspectos de la cuestión social. Las impresiones que Moreno se llevaba de sus visitas a los lugares de trabajo, nutrieron tanto a sus novelas populares como a sus notas periodísticas que, a veces, coincidían punto por punto.

7 Existen trabajos que desde el marxismo revisan la infravaloración de la importancia de la raza, la etnicidad, el género y la nacionalidad en la formación de clase que caracterizaban a los estudios marxistas tradicionales. Estos seguían la idea de Marx, quien esperaba que el proceso de proletarización diera lugar, con el paso del tiempo, a una clase obrera cada vez más homogénea, en la que convergerían experiencia, intereses y conciencia, sentándose así las bases de un movimiento obrero unificado a escala nacional e internacional. Silver analiza la acción colectiva de los trabajadores llegando a la conclusión de que muchas veces se establecen fronteras y límites que no responden a un criterio de clase como fundamento de las reivindicaciones obreras. Ver Beverly Silver (2005). 